\title{
O ESTUDO DA DEMANDA E DAS NECESSIDADES E SUA IMPORTÂNCIA PARA O PLANEJAMENTO DE SAÚDE
}

Oswaldo CAMPOS (1)

\begin{abstract}
Campos, O. - O estudo da demanda e das necessidades e sua importância para o planejamento de saúde. Rev. Saúde públ., S. Paulo, 3(1):79-81, jun. 1969.

Resumo - O trabalho procura discutir os conceitos de demanda e de necessidades em saúde e sua importância para o planejamento. Conceituando saúde como o estado de melhor adaptação do individuo ao ambiente em que vive e "necessidade em saúde" como tudo o que contribui para tal adaptação, o trabalho chama a atenção para o fato de que "demanda" é um conceito histórico particular a um determinado tipo de economia e ligado a poder aquisitivo individual. Conclui recomendando aos técnicos em planejamento de saúde a substituição da "demanqa" por "necessidades" nas técnicas atualmente utilizadas.
\end{abstract}

O objetivo do presente trabalho é discutir os conceitos de "demanda" e de "necessidade" e a importância dos mesmos para o planejamento de saúde em um sistema de economia mista.

Um sistema de economia mista caracteriza-se pela existência, no seio do universo econômico, de duas esferas de interêsses: a pública e a privada e pela participação crescente do Estado, por inúmeras razões, na vida econômica, quer em serviços tradicionais, quer em novas atividades de produção e de promoção.

Em um sistema dêste tipo, o papel clássico do "mercado" é complementado por outros mecanismos tendentes a corrigí-lo e aperfeiçoá-lo.

"O MERCADo é o "local" onde os detentores de rendimento, em busca de satisfação de suas necessidades e desejos encontram-se com os ofertantes de bens e serviços dispostos a cedê-los a determinados preços. E aí que a produção atinge o seu destino final sendo adquirida pelos membros da comunidade, segundo o seu poder de compra. 0 volume de bens e serviços, que a comunidade está disposta a adquirir a determinados preços dimensiona a DEMANDA e a quantidade de bens e serviços que os empresários lançam no mercado, mediante retribuição financeira constitui a OFERTA" (CAstro \& Lessa, 1967).

Em uma economia de mercado, o volume de bens e serviços transacionados está na dependência da renda individual $\mathrm{e}$ da importância relativa atribuída aos mes-

Recebldo para publicação em 6-3-1969.

(1) Do Departamento de Metodologia do Planejamento da Fundação Ensino Especializado de Saúde Pública - Rio de Janeiro, Brasil. 
CAMPOS, O. - o estudo da demanda e das necessidades e sua importáncia para o planejamento de saúde. Rev. Saúde puibl., S. Paulo, 3(1):79-81, jun. 1969.

mos, não sendo, obrigatòriamente, consideradas as necessidades de todos os indivíduos. $\mathrm{Na}$ verdade, apenas aquêles dotados de suficiente capacidade de compra participarão do mercado, dando origem a uma demanda e conseqüentemente a uma oferta.

As necessidades em saúde, contudo, não são uma categoria ligada ao "status" econômico, mas sim inerentes ao indivíduo e sua satisfação é imperativa, tanto para a sobrevivência da espécie, quanto para o perfeito funcionamento da sociedade. Sendo uma decorrência do problema existencial do homem, elas se manifestam em tipos e graus diferentes de acôrdo com o modêlo de organização social. Conseqüentemente, as formas de seu atendimento variam conforme a intensidade da manifestação, o estágio de desenvolvimentọ da comunidade, o nivel de percepção da necessidade pela população e a importância que ela assume para o bem-estar.

Nas civilizações mais antigas os sacerdotes, magos e filósofos supriam algumas das necessidades individuais $e$ os códigos sociais enumeravam medidas coletivas para minorar os efeitos das doenças na comunidade, bem como para tornar o ambiente menos hostil. $\mathrm{O}$ aparecimento e aperfeiçoamento constantes da medicina são respostas à permanente diversificação e crescimento das solicitações.

Mais recentemente, a complexidade do problema deu ensejo ao aparecimento de uma tecnologia social mais adequada à sua solução: a saúde pública.

Ao mesmo tempo que aumentam as necessidades em saúde e que os conhecimentos sôbre as mesmas evoluem, surgem novos mecanismos de solução da problemática. Em determinado momento aparece um verdadeiro "mercado de bens e serviços de saúde", cujo funcionamento na sua essência é regido pelas leis da oferta e da procura. Por outro lado, o Estado, reconhecendo a importância cada vez maior da saúde como componente do bem-estar e como fator de desenvolvimen- to, procura interferir ativamente no processo de aquisição, manutenção e melhoria da saúde. Busca, assim, oferecer um mínimo de serviços a que todos os indivíduos têm direito independentemente de sua capacidade aquisitiva própria, de tal forma que o desenvolvimento e o bem-estar sejam alcançados mais eficientemente e ao menor custo social.

Ocorre, porém, que os recursos destinados à satisfação das necessidades em saúde são limitados. Este fato, que se reproduz ao nível dos outros setores e da sociedade como um todo, leva ao reconhecimento da existência de um jôgo de concorrência por recursos escassos o que empresta à problemática de saúde uma conotação de problemática econômica e de planejamento.

A existência de necessidades múltiplas e crescentes em saúde bem como de mecanismos variados para o seu atendimento, constituem a moldura dentro da qual o problema deve ser enfocado. A solução deve ser racional, eficiente e ter como objetivo, não apenas, satisfazer os aparentes desejos da comunidade, mas contribuir para a obtenção do máximo de bem-estar.

Vale ressaltar que em qualquer momento existem necessidades sentidas e não sentidas. Ambas podem ou não ser técnica e socialmente justificadas. Cabe ao técnico em saúde identificar, quantificar e valorizar a soma total de necessidades, a parcela já satisfeita e o "deficit" existente. Além disso, é de sua responsabilidade programar ações que além de atender ao "deficit" presente e futuro, aumentem a eficiência do sistema e eliminem progressivamente as necessidades não justificadas.

$O$ instrumento adequado para a abordagem racional do problema é o PLANEJAMENTO.

Sua seqüência metodológica permite identificar o nível de saúde vigente em uma área, estudar a natureza e a eficiência do conjunto das ações empreendidas e a disponibilidade geral de recursos. Comparando tal situação com um modêlo, construído a partir da disponibilidade de 
CAMPOS, O. - O estudo da demanda e das necessidades e sua importância para o planejamento de saúde. Rev. Saúde públ., S. Paulo, 3(1):79-81, jun. 1969.

recursos e do nivel do conhecimento vigente, é possível concluir pelo seu grau de satisfatoriedade e mutabilidade, derivando daí as necessidades. A fixação de metas é a próxima etapa do processo sequencial do planejamento. A maior adequação das mesmas e a sua contribuição para o bem-estar serão consequiências do grau de racionalidade do processo.

Implícitas a todo o mecanismo acima estão as exigências de definir estado e nível de saúde, de quantificar e de estabelecer mecanismos apropriados de execução e de avaliação.

Fundamentalmente, a saúde é um pro. blema de definição social, cabendo aos técnicos definí-la dentro de um contexto histórico e socialmente determinado. Em outras palavras, para cada área e em cada momento existe um nível de saúde que é, em última análise, o estado de melhor adaptação do indivíduo ao meio em que êle vive. Tudo o que permite a aquisição e a manutenção dêsse estado configura uma NECESSIDADE que deve ser atendida na medida da disponibilidade de recursos e segundo um esquema racional de prioridades.

òbviamente, em tal esquema a DEMANDA, no sentido convencional do têrmo não pode ser aceita como indicador de necessidades, desde que ela é afetada por inúmeros fatôres, entre os quais o desejo de lucro por parte do empresário privado, a percepção deficiente por parte do usuário e as decisões nem sempre racionais por parte dos demais ofertantes de serviços de saúde. A alternativa é estabelecer mecanismos adequados para identificar não apenas os níveis de saúde como as suas causas reais e então definir as verdadeiras NECEssidades em saúde. Para tal fim são recomendados entre outros meios, inquéritos de morbidade, estudos epidemiológicos e levantamento de recursos humanos e materiais.

0 atendimento racional da problemática de saúde passa então a ser ìntimamente relacionado à capacidade de oferta da sociedade em confronto com necessidades. A oferta por sua vez é influenciada pela parcela da Renda Nacional destinada à saúde em um mecanismo de confrontação intersetorial, pela eficiência operacional das instituições, pelas atitudes da comunidade e pela importância que a saúde adquire, como "insumo crítico" em determinadas fases do processo de desenvol. vimento.

A partir dêsse momento, isto é, fixadas prioridades, conhecidas necessidades e capacidades de satisfação, e estabelecidas metas, a problemática se transfere para o âmbito da execução. Em um sistema de economia mista, a decisão fundamental sô. bre quem deve executar as ações é matéria de decisão política que transcende ao nível do planejamento. Cabe a êste oferecer subsídios para que o nivel decisório maneje racionalmente os instrumentos de que dispõe para a consecução de seus objetivos.

As considerações acima nos permitem encarecer a urgência de realizar estudos visando identificar as reais necessidades em saúde e recomendar aos técnicos de planejamento de saúde a substituição, em seus esquemas operacionais da variável DEMANDA satisfeita por NECESSIDADE em saúde.

Campos, O. - On the importance of the demand and needs for health planning. Rev. Saúde puibl., S. Paulo, 3(1):79-81, jun. 1969.

Summary - The paper is concerned with health planning in a market economic system. The author after discussing the concepts of "demand" and "necessity" related to health planning stresses the importance of considering such problems in the current techniques of health planning.

\section{REFERENCIA BIBLIOGRAFICA}

CASTRO, A. B. \& LESSA, C. F. - Introdução à economia. Rio de Janeiro, Ed. Forense, 1967. p. 29. 